
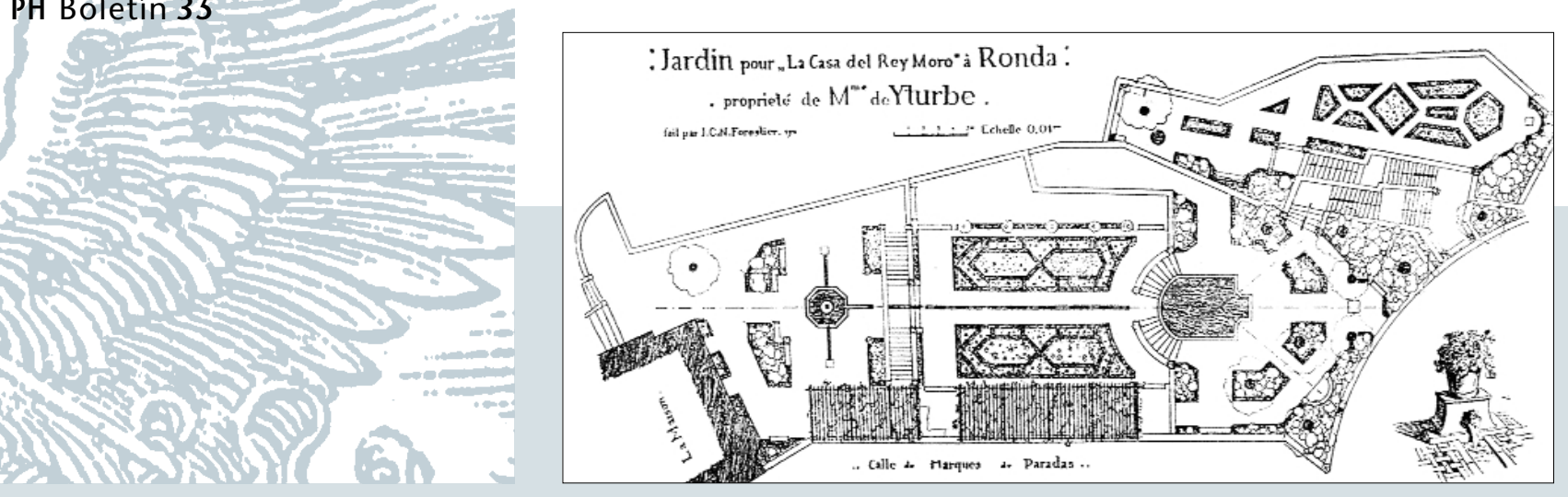

\title{
Sobre la difusión de los jardines históricos (Forestier en El Monte)
}

Aunque la Ley Andaluza del Patrimonio Histórico reconoce como Bien Cultural a los Jardines Históricos y se están llevando a cabo tímidos procesos de intervención -principalmente inventarios, alguna apertura de expediente de incoación,..., pocas restauraciones y casi siempre basadas en los elementos arquitectónicos del jardín-, los procesos de restauración, salvo escasas y honrosas excepciones, se encuentran aún fuera de los clásicos circuitos de tutela que las instituciones encargadas de velar por el patrimonio tienen establecidos, llevándose a cabo estas tareas de forma totalmente arbitraria, sin aplicación de la normativa o de las recomendaciones que para tal fin autoridades en la materia han realizado - La Carta de Florencia, sin ir más lejos- y donde la falta de rigor científico da lugar en muchos casos a pasar por restauración lo que no es otra cosa que la destrucción de un jardín para crear otro que se adapte a los nuevos gustos o necesidades de la población en la que se encuentra ubicado.

Triste ejemplo de ello es el jardín neoclásico del palacio ducal de Fernán-Nuñez, en Córdoba.

Cierto es que existe una carencia manifiesta de profesionales que puedan dedicarse a estos trabajos, y que los equipos requieren una gran multidisciplinariedad y una perfecta coordinación, lo que los hace costosos. Pero no hay que olvidar que la arquitectura del paisaje usa como material principal a seres vivos, y que el ciclo vital de un jardín es más largo de lo que muchos de nosotros imaginamos. Por ejemplo, rara vez las personas que participaron en su creación llegan a conocerlo en su momento de máximo esplendor.

Por tanto, el ejercicio de abstracción que supone el diseño, la creación de un jardín, no está exento de connotaciones metafísicas. A fin de cuentas, creamos un espacio con seres vivos que posteriormente cultivamos - damos instrucción, educamos, cuidamos-, con una finalidad, dotándolos de un espíritu, de una simbología y de una cosmogonía.

Además, todo jardín nace con vocación de jardín histórico.
Pero cincuenta años, casi una vida humana, sólo representa la primera edad de un jardín, su juventud, y es a partir de ese momento, cuando el paso de una y otra generación comience a estratificarse, cuando el jardín esté presente en las vidas de sus usuarios desde la infancia hasta la vejez, justamente en ese momento podremos decir que el jardín estará acabado.

Por tanto, las líneas arquitectónicas/paisajísticas, el trazado sobre el plano, es el punto de partida, raras veces el de llegada, porque de suma importancia son "las sugerencias mutuas" de un jardín, sugerencias del hombre a la naturaleza y de la naturaleza al hombre, que lo modelan y enriquecen, y que requieren un profundo y delicado estudio, lleno de conceptos culturales ajenos a la escuadra y el compás.

Y si en términos de intervenciones de restauración de jardines históricos estamos -tanto a nivel estatal como en nuestra comunidad autónoma- muy alejados de la media europea, en similares condiciones se encuentra la difusión de estos productos patrimoniales.

Escasísimos son los focos de difusión que trabajan el tema de los jardines históricos y generalmente se desaprovechan las oportunidades que para ello nos brindan los estudios, las monografías, los artículos, los documentales y las ediciones de guías histórico-artísticas y/o turísticas en las que se analizan el patrimonio inmueble y mueble, y en algunos casos se nombra, casi de pasada, "su hermoso jardín", reseñando a lo sumo algunos elementos de la obra civil o decorativo no vegetal -fuentes, bancos, pérgolas,... esculturas-.

El panorama, por tanto, no se presenta en principio muy favorable para una correcta salvaguardia de nuestros jardines históricos. Por eso la aplicación de la ecuación "Difusión = Conservación Preventiva" es la mejor herramienta que los profesionales que nos dedicamos a este campo patrimonial podemos manejar.

Como fruto de este planteamiento, desde Enero y hasta finales de Mayo de este año se ha venido desarrollando en la Fundación EI Monte una serie de conferencias que, bajo el título "El Legado de Forestier en Andalucía" tienen como objetivo profundizar en el conocimiento de la obra que este arquitecto paisajista francés desarrolló en Andalucía durante las primeras décadas del siglo XX.

Para ello, se ha articulado un programa en el que, haciendo un recorrido multidisciplinar, se asiste al proceso de creación de estos cuatro jardines - dos en Sevilla, parque de $M^{a}$ Luisa y Colegio Mayor Virgen del Buen Aire, uno en la provincia de Córdoba, finca de Moratalla, y otro en la de Málaga, Casa del Rey Moro- a la vez que se analizan las influencias que la estancia en nuestras tierras tuvo en algunas de sus obras posteriores, del que es el más rico ejemplo el Jardín Hispano-musulmán de Joseph Guy en Bèziers, Francia.

Como el eje transversal de este ciclo es la conservación de los jardines históricos, no sólo se está haciendo especial hincapié en los diferentes estilos jardineros, en la historia del jardín o de la jardinería, en el diseño paisajista, y en los métodos y técnicas de la restauración de los jardines así como en la normativa que protege a estos bienes culturales, sino que se está incidiendo de manera directa en esa vertiente inmaterial, provocadora de fuertes emociones -bellas, alegres o melancólicas, recordadas siempre y añoradas a veces-, que tienen los jardines. A fin de cuentas, en la vida de una persona casi siempre ha existido un jardín, o un patio, o una arboleda...

Puesto que la respuesta del público objetivo está siendo muy positiva, la fundación El Monte tiene previsto reprogramar este ciclo a partir de Octubre del año en curso y, además, iniciar otro bajo el título "Jardines históricos de Andalucía", aportando con ello un enorme grano de arena al vacío que existe respecto a este fabuloso campo de nuestro patrimonio cultural, acertadamente llamado por Forestier: "lugares de reposo, dominios de poesía".

Raquel Viñuales Meléndez 